This document is the accepted manuscript version of the following article:

Nguyen, B. N., Adrio, L. A., Barreiro, E. M., Brazier, J. B., Haycock, P., Hii, K. K.

(M. ) , ... Szlachetko, J. (2012). Deconvolution of the mechanism of homogeneous gold-

catalyzed reactions. Organometa11ics, 31(6), 2395-2402. https://doi.org/10.1021/om300030e

\title{
Deconvolution of the mechanism of homogeneous
}

\section{gold-catalyzed reactions}

Bao N. Nguyen, ${ }^{[a]} *$ Luis A. Adrio, ${ }^{[a]}$ Elena M. Barreiro, ${ }^{[a]}$ John B. Brazier, ${ }^{[a]}$ Peter Haycock, ${ }^{[a]}$ King Kuok (Mimi) Hii, ${ }^{[a]}$ Maarten Nachtegaal, ${ }^{[b]}$ Mark A. Newton, ${ }^{[c]}$ Jakub Szlachetko. ${ }^{[b]}$

[a] Department of Chemistry, Imperial College London, South Kensington, London, SW7 2AZ, UK.

[b] Paul Scherrer Institut, 5232 Villigen PSI, Switzerland.

[c] European Synchrotron and Radiation Facility, 6, rue Jules Horowitz, 38000 Grenoble, France.

RECEIVED DATE (to be automatically inserted after your manuscript is accepted if required according to the journal that you are submitting your paper to)

TITLE RUNNING HEAD (Word Style “AF_Title_Running_Head”). If you are submitting your paper to a journal that requires a title running head (condensed title appearing at the top of the journal page), please provide a 50-character or less summary of the title of the manuscript.

\section{CORRESPONDING AUTHOR FOOTNOTE}

Dr Bao N. Nguyen, Department of Chemistry, Imperial College London, South Kensington, London, SW7 2AZ, b.nguyen@imperial.ac.uk

ABSTRACT: The role of chiral counterion in gold-catalyzed asymmetric intramolecular hydroamination/hydroalkoxylation reaction of allenes and the oxidation state of gold catalyst in benzannulation of 2-carbonylphenylalkynes have been investigated using XAFS at the L3 edge of gold. Fitting of experimental data indicated a bond between cationic gold and a BINOL-phosphate 
anion in solution. ${ }^{31} \mathrm{P}$ NMR confirmed this phosphate group is likely not to be labile and may stay bonded to the gold catalyst during the catalytic cycle. In the benzannulation reaction, XAFS analysis suggested the majority of gold species obtained from reacting starting material with $\mathrm{AuCl}_{3}$ to be $\mathrm{Au}(\mathrm{III})$ complexes. NMR and mass spectrometry characterization lead to the previously unobserved intermediate 10. Gem-diaurate complexes, which have been previously proposed as possible intermediates, were not detected.

KEYWORDS: solution-based EXAFS, gold catalysis, chiral counterion, gold oxidation state.

BRIEFS: The nature of gold catalyst-chiral counterion interaction in gold-catalyzed asymmetric intramolecular hydroamination/hydroalkoxylation reactions of allenes and oxidation state of gold catalyst in benzannulation are deconvoluted using a combination of solution-based EXAFS, NMR, and mass spectrometry. 


\section{Introduction}

The last decade has seen rapid development of homogeneous gold catalysis in several important classes of synthetic transformations. ${ }^{1}$ The unique reactivity of gold allows selective activation of alkynes, allenes and $\mathrm{C}-\mathrm{H}$ bonds in the presence of other functional groups, which may prove challenging for many other transition metal catalysts. Surprisingly, little is understood about the real active catalytic species. Most gold-catalyzed mechanisms are proposed based on little evidence other than a loose analogy to other transition metal catalyzed processes. ${ }^{2}$ Characterization of catalytic intermediates has been difficult due to either fast reactions or complicated reaction mixtures. Well characterized intermediates to date are often stabilized resting states with bulky ligands, which may or may not be catalytically relevant. ${ }^{2}$ In addition, the mechanism of homogeneous gold catalysis and the nature of the true catalytic species are often further complicated by the easy interconversion between $\mathrm{Au}(\mathrm{I})$ and $\mathrm{Au}(\mathrm{III})$ species under reaction conditions. ${ }^{1 \mathrm{c}}$ Theoretical studies to delineate this problem have so far proven inconclusive. ${ }^{3}$

In this context, solution-based X-ray Absorption Fine Structure spectroscopy (XAFS) offers an alternative tool to study catalytic intermediates. As the technique is element specific, the catalytic cycle can be observed under realistic catalytic conditions without interference from organic starting materials and products. Furthermore, the XANES and EXAFS regions are sensitive to coordination number and different types of ligands around the metal center. ${ }^{4}$ Consequently, discerning the oxidation state and bonding state of gold intermediates may be possible. When this is employed in conjunction with other more traditional mechanistic tools, significant mechanistic understanding can be gained. The effectiveness of this approach has been clearly demonstrated by Evans, ${ }^{5}$ Bertagnolli, ${ }^{6}$ Tromp, ${ }^{7}$ Baiker, ${ }^{8}$ and Koningsberger. ${ }^{9}$ In addition, this powerful combination has been employed by two of us to elucidate the two-step process (oxidative addition followed by cis-trans isomerization) for addition of iodobenzene to $\left[\left(\mathrm{Ph}_{3} \mathrm{P}\right)_{2} \mathrm{Pd}(\mathrm{dba})\right] .{ }^{10}$ While UV-Vis/stopped-flow data gave important information on the kinetics and electronic state of palladium, EXAFS was used to determine bonding changes in the first coordination shell around palladium. More recently, Hashmi and Bertagnolli 
used EXAFS to successfully exclude the presence of nanoparticles and to monitor the oxidation state of their catalyst during a catalytic oxidation of aldehydes to esters. ${ }^{11}$

In this communication we report our studies of two different gold-catalyzed reactions using solution EXAFS at the L3-edge $(11.919 \mathrm{keV})$ in combination with more traditional analytical tools, i.e. NMR and mass spectrometry. The two selected reactions are an enantioselective intramolecular hydroalkoxylation of allenes, catalyzed by a gold-phosphine complex containing a chiral phosphate counterion reported by $\operatorname{Toste}^{12}$ and a benzannulation of 2-carbonylphenylalkynes reported by Yamamoto. ${ }^{13}$ These are synthetically important reactions which represent characteristic reactivities of gold catalysts: activation of allenes and alkynes for nucleophilic attack by heteroatoms. They also pose important mechanistic questions: the interaction between a chiral counterion and the catalyst of a highly enantioselective reaction and the oxidation states of gold catalysts involved in these catalytic reactions.

\section{Gold-catalyzed enantioselective intramolecular hydroalkoxylation}

The asymmetric intramolecular hydroalkoxylation and hydroamination of allenes reported by Toste $^{12}$ remains one of few examples of a highly enantioselective transition metal catalyzed reaction in which a counteranion acts as the sole source of chirality (Scheme 1). ${ }^{14}$ Attempts using other chiral counterions in rhodium-catalyzed asymmetric hydrogenation and copper-catalyzed aziridination have so far failed to achieve enantioselectivity higher than $80 \%{ }^{15}$ The dependence of the enantioselectivity on solvent polarity suggests that the ion pair interactions are important in the enantio-determining step. The concept is potentially applicable to a wide range of reactions catalyzed by cationic transition metal complexes with a small library of chiral counterions replacing the very large library of chiral ligands currently in use. However, little else is understood about how the counterion affects the stereochemical outcome of the reaction and whether the phosphate binds to the gold catalyst during the catalytic cycle. 


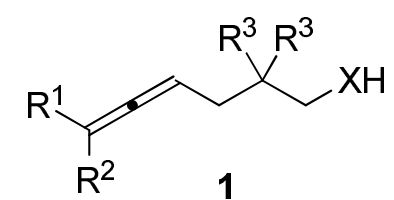

$\mathrm{R}^{1}, \mathrm{R}^{2}=\mathrm{H}, \mathrm{Me},\left(\mathrm{CH}_{2}\right)_{4},\left(\mathrm{CH}_{2}\right)_{5}$

$\mathrm{R}^{3}=\mathrm{H}, \mathrm{Me},\left(\mathrm{CH}_{2}\right)_{5}$

$\mathrm{XH}=\mathrm{OH}, \mathrm{NHSO}_{2}$ Mes
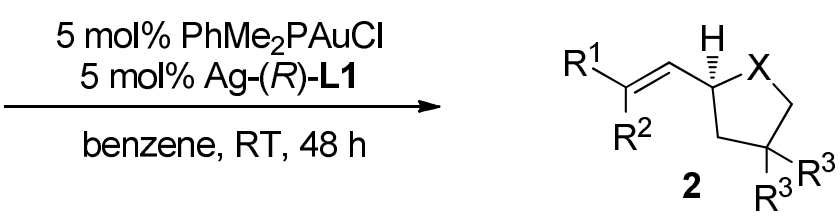

$73-97 \%$ yield

$96-98 \%$ ee<smiles>[R]c1cc2ccccc2c(-c2c([R])cc3ccccc3c2OP(=O)([O-])O)c1[R]</smiles>

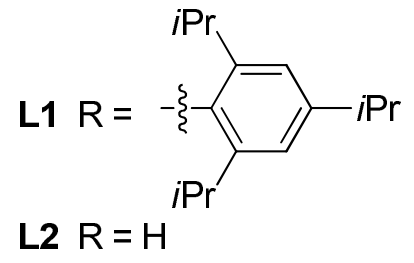

Scheme 1. Gold-catalyzed asymmetric hydroamination and hydroalkoxylation of allenes using chiral phosphates as the sole source of chirality.

As gold(I) complexes are commonly found in a linear geometry with coordination number of 2 , the initial assumption was to disfavor direct bonding between cationic gold catalysts and chiral counterions. Nevertheless, complexes with coordination number $>2$ are known. ${ }^{16}$ This means a gold atom can coordinate to a phosphine ligand, a phosphate anion and an allene at the same time. Additionally, Mikami and co-workers reported a crystal structure of BIPHEP(AuL1 $)_{2}\left(\mathbf{L 1}=3,3^{\prime}-\right.$ phenyl-1,1'-binaphthyl-2,2'-diyl hydrogenphosphate), ${ }^{17}$ whereby each gold atom is coordinated with one phosphorus, one phosphate $\mathbf{L} \mathbf{1}$ and the other gold atom (bond lengths $\mathrm{Au}-\mathrm{O}=2.066 \AA, \mathrm{Au}-\mathrm{P}=$ $2.207 \AA, \mathrm{Au}-\mathrm{Au}=2.994 \AA$ ) in a T-shape geometry (Figure 1). The Au-O distance indicates strong bonding between the gold cation and the phosphate. However, the ${ }^{31} \mathrm{P}$ NMR signal of the phosphate of BIPHEP $(\mathrm{AuL1})_{2}$ in benzene- $d_{6}$ is broaden, presumably due to dynamic behavior. Unfortunately, the cause of this dynamic behavior, e.g. dissociation/coordination of the phosphates or conformational changes of the large phosphates, was not further investigated, and it is unknown whether the $\mathrm{Au}-\mathrm{O}$ bond is retained in solution. 


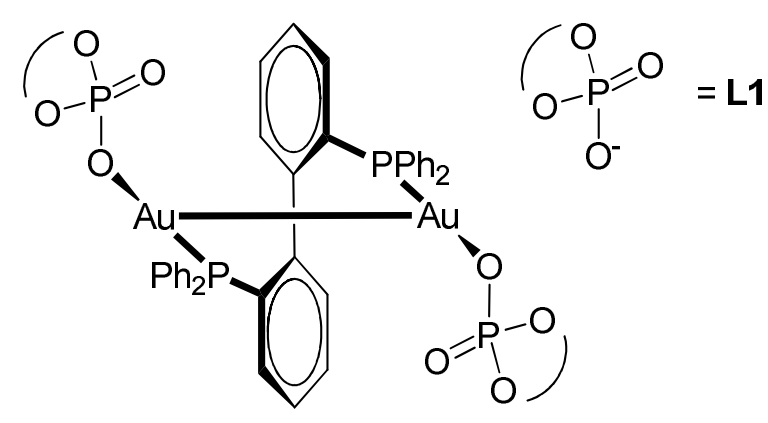

Figure 1. Structure of BIPHEP(AuL1)

To answer this question, XAFS spectra of a solid sample of $\mathrm{Ph}_{3} \mathrm{PAuCl}$ and a solution of $\mathrm{Ph}_{3} \mathrm{PAuL2}$ (L2 = 1,1'-binaphthalene-2,2'-diyl hydrogenphosphate) in toluene were recorded. Ligand $\mathbf{L 1}$ and the best catalyst system $(\mathrm{dppm}) \mathrm{Au}_{2} \mathrm{Cl}_{2} / \mathbf{L 1}$ reported by Toste was not measured due to very poor solubility in suitable solvents which can allow sufficient transmission at $9 \mathrm{keV}$, and rapid decomposition upon X-ray radiation. ${ }^{12}$ A catalytic reaction using the $\mathrm{Ph}_{3} \mathrm{PAuCl} / \mathrm{Ag}-\mathbf{L} 2$ catalyst $(2$ mol\%) with substrate $1\left(\mathrm{XH}=\mathrm{OH}, \mathrm{R}^{1}, \mathrm{R}^{2}=-\left(\mathrm{CH}_{2}\right)_{4}-, \mathrm{R}^{3}=\mathrm{Me}\right)$ was performed as described by Toste to give $100 \%$ conversion in 1 hour compared to 18 hours using (dppm) $\mathrm{Au}_{2} \mathrm{Cl}_{2} / \mathbf{L} \mathbf{1}$. A lower enantiomeric excess, $11 \%,{ }^{18}$ was obtained, but it was considered substantial enough to investigate how the chiral phosphate influences the stereochemical outcome.

The solution of $\mathrm{Ph}_{3} \mathrm{PAuL2}$ was prepared by stirring a suspension of $\mathrm{Ph}_{3} \mathrm{PAuCl}$ with 1.0 equivalent of Ag-L2 under anhydrous conditions for 30 minutes before filtering through $0.2 \mu \mathrm{m}$ syringe filter to remove silver chloride. ${ }^{19}$ XAFS measurements were recorded in transmission mode at the SuperXAS beam line at the Swiss Light Source, Villigen. X-ray beam damage on the samples was found to be insignificant for the first 15 minutes and the spectra were collected in 2-minute scans which were checked before being merged. The difference in signal-to-noise ratio between the two spectra, $\mathrm{Ph}_{3} \mathrm{PAuCl}$ (solid) and $\mathrm{Ph}_{3} \mathrm{PAuL2}$ (solution), was due to moving from a solid to a solution sample (Figure 2). After careful background subtraction, a new shoulder was identified at about $1.5 \AA$ in $R$-space upon removal of chloride from $\mathrm{Ph}_{3} \mathrm{PAuCl}$ using $\mathrm{Ag}-\mathbf{L} 2$. 

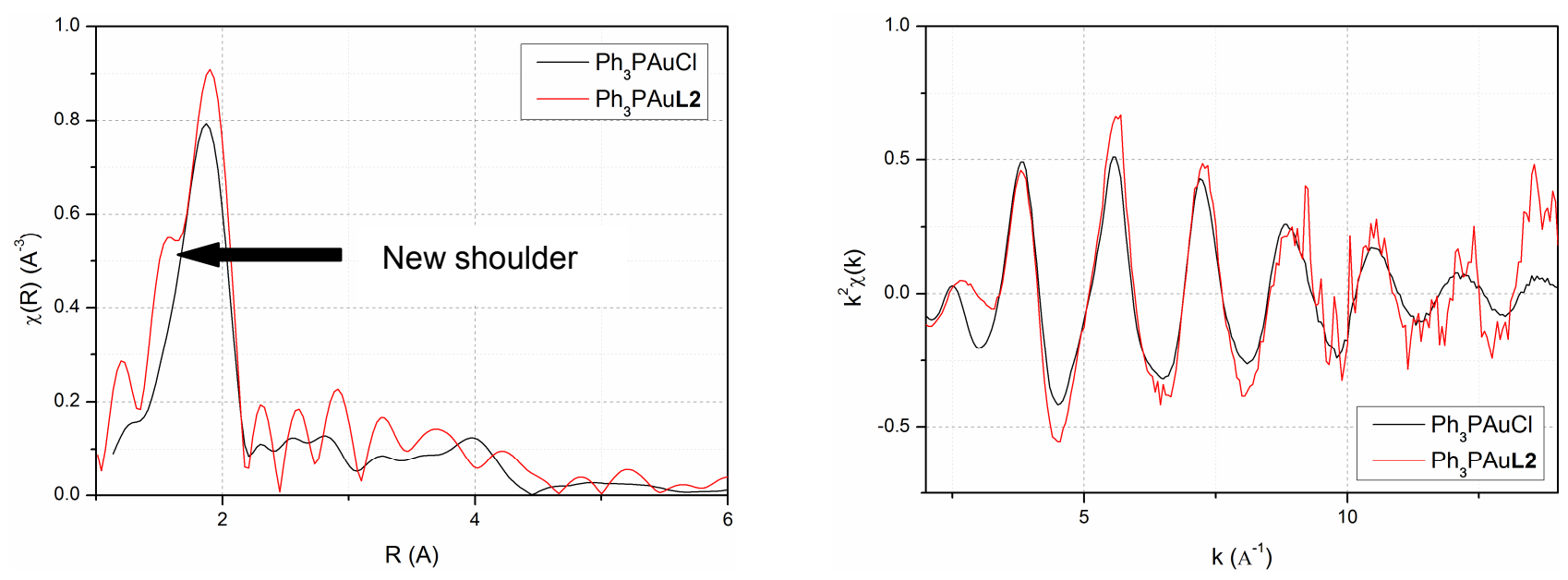

Figure 2. EXAFS spectra of $\mathrm{Ph}_{3} \mathrm{PAuCl}$ (solid sample due to low solubility) and $\mathrm{Ph}_{3} \mathrm{PAuCl} / \mathrm{Ag}-\mathbf{L} 2$ (50 mM solution in toluene) in $R$-space (left, $k^{1}$-weighting) and $k$-space (right, $k^{2}$-weighting).

A solvent stabilized $\left[\mathrm{Ph}_{3} \mathrm{PAu}\right]^{+} \cdot$ Toluene species was considered with possible scattering from the toluene molecule responsible for the observed peak. Without any similar reported crystal structure in the literature, the structure of the species was obtained using ab initio method (Figure 3, DFT B3LYP/LANL2DZ). The solvent molecule was found to bind to the gold cation via its para position, with the $\mathrm{Au}-\mathrm{C}($ para $)-\mathrm{C}(\mathrm{Me})$ angle being $99.6^{\circ}$. Most importantly, the $\mathrm{Au}-\mathrm{C}($ para $)$ and $\mathrm{Au}-\mathrm{P}$ distances were $2.318 \AA$ and $2.395 \AA$, respectively. Neither of these could account for the observed new peak at $1.5 \AA$ above (see Table S4, supporting information). It was consequently hypothesized that this new peak of $\mathrm{Ph}_{3} \mathrm{PAuL2}$ corresponds to an $\mathrm{Au}-\mathrm{O}$ bond between the gold cation and phosphate. 


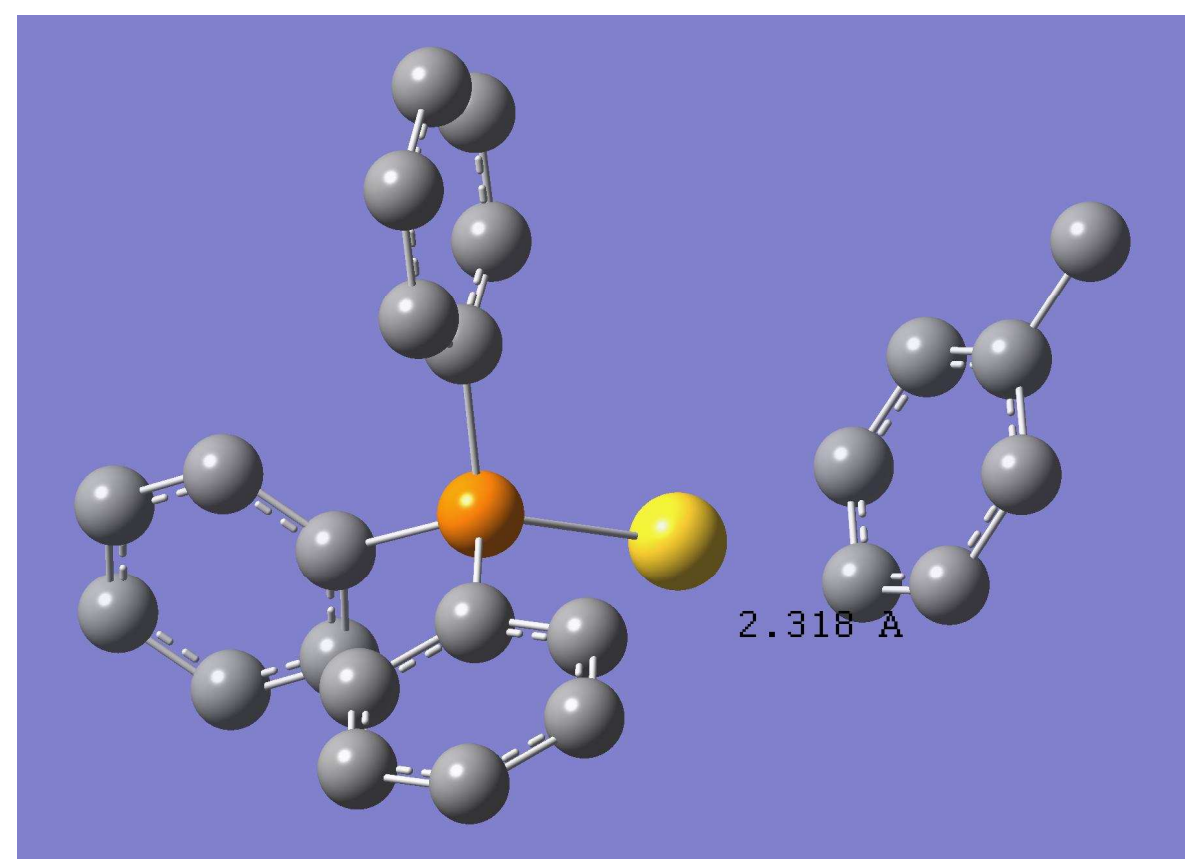

Figure 3. Optimised structure of $[\mathrm{Ph} 3 \mathrm{PAu}]^{+} \cdot$ Toluene using DFT B3LYP/LANL2DZ (hydrogen atoms are omitted for clarity).

To verify this, fitting was performed with structures 3 and $\mathbf{4}$ (Table 1) using the IFEFFIT package and the results are summarized in Table $1 .^{20}$ Using structure 4 (without an $\mathrm{Au}-\mathrm{O}$ bond), a poor fitting between FEFF6 theory and experimental data was obtained with R-factor $=15.5 \%$. Furthermore, the shoulder at around $1.5 \AA$ in $R$-space could not be accounted for without a negative value of the Debye-Waller factor. Structure 3, on the other hand, can be fitted to experimental data with reasonable confidence despite the low quality of the data (R-factor $=3.7 \%$, Figure 4$)$. Importantly, the contribution from the phosphate oxygen atom was found to be responsible for the observed shoulder at $1.5 \AA$ as predicted. Multiple-scattering contributions from the linear $\mathrm{P}-\mathrm{Au}-\mathrm{O}$ path also accounts for most of the signal at $\mathrm{R}>3 \AA$ in $R$-space, which theoretical calculation of structure 4 is unable to fit.

Table 1. EXAFS analysis of two models for $\mathrm{Ph}_{3} \mathrm{PAuCl} / \mathrm{Ag}-\mathbf{L} 2$ solution ${ }^{[\mathrm{a}]}$

\begin{tabular}{|l|c|c|c|c|c|}
\hline Model & Neighbour & $\mathrm{CN}^{[\mathrm{b}]}$ & $\mathrm{R}(\AA)^{[\mathrm{c}]}$ & $\sigma^{2}\left(\AA^{-2}\right)^{[\mathrm{d}]}$ & $\Delta \mathrm{E}_{0}(\mathrm{eV})^{[\mathrm{e}]}$ \\
\hline With $\mathrm{Au}-\mathrm{O}$ bond & $\mathrm{O}$ & 1.0 & $2.0210 \pm$ & $0.007 \pm 0.003$ & $5.15 \pm 1.81$ \\
& & & & & \\
\hline
\end{tabular}




\begin{tabular}{|c|c|c|c|c|c|}
\hline R-factor $=3.7 \%$ & & & 0.0246 & & \\
\hline $\begin{array}{l}\text { Reduced chi-square }=57.5 \\
\qquad-\mathrm{C}_{\mathrm{C}}^{\mathrm{C}}-\mathrm{Au}-\mathrm{O}^{\prime}\end{array}$ & $\mathrm{P}$ & 1.0 & $\begin{array}{c}2.2735 \pm \\
0.0086\end{array}$ & $\begin{array}{c}0.0004 \pm \\
0.0006\end{array}$ & \\
\hline $\begin{array}{l}\text { Without } \mathrm{Au}-\mathrm{O} \text { bond } \\
\text { R-factor }=15.5 \% \\
\text { Reduced chi-square }=303.9 \\
\text { C } 4-\mathrm{Au}^{+}\end{array}$ & $\mathrm{P}$ & 1.0 & $\begin{array}{c}2.2628 \pm \\
0.0149\end{array}$ & $\begin{array}{c}-0.0005 \pm \\
0.0009\end{array}$ & $2.41 \pm 2.73$ \\
\hline
\end{tabular}

Fit over $k$-range 2-15 and $R$-range 1-4.5 ${ }^{[a \mid}$ Parameters in italics were restricted in the fit (see experimental procedure). ${ }^{[\mathrm{b}]}$ Coordination number, set by $\mathrm{N}=1, \mathrm{~S} 02=1.0$ in Artemis (see supporting information for determination of $\mathrm{S} 02$ value). ${ }^{[c]}$ Interatomic distance. ${ }^{[\mathrm{d}]}$ Debye-Waller factor. ${ }^{[\mathrm{e}]}$ Energy variation in Fermi level from theory.

The structural parameters of $\mathrm{Ph}_{3} \mathrm{PAuL2}$ in solution obtained by fitting EXAFS data with structure 3 are slightly different from the reported crystal structure of the similar compound BIPHEP(AuL1 $)_{2}$. The $\mathrm{Au}-\mathrm{O}$ and $\mathrm{Au}-\mathrm{P}$ bond lengths of $\mathrm{Ph}_{3} \mathrm{PAuL2}$ were determined to be $2.021 \AA$ and $2.274 \AA$, respectively. The Au-O bond length is shorter than that of BIPHEP(AuL1) $2(2.066 \AA) .{ }^{21}$ This could be explained by the greater steric bulk of phosphate $\mathbf{L 1}$ compared to that of $\mathbf{L 2}$. The shorter $\mathrm{Au}-\mathrm{O}$ bond of $\mathrm{Ph}_{3} \mathrm{PAuL2}$ may exert a greater trans influence, which could lead to a longer $\mathrm{Au}-\mathrm{P}$ bond $\left(2.207 \AA\right.$ in $\left.\operatorname{BIPHEP}(\mathrm{AuL1})_{2}\right) .{ }^{22}$ In the case of structure 4, the positive charge on gold should lead to a shorter $\mathrm{Au}-\mathrm{P}$ bond compared with that of $\mathrm{Ph}_{3} \mathrm{PAuCl}(2.233 \AA)$, which was not observed. Our experimental finding therefore strongly favors a short bond between the gold cation and the phosphate anion $\mathbf{L} 2$ of $\mathrm{Ph}_{3} \mathrm{PAuL2}$ in toluene solution. 
(a)
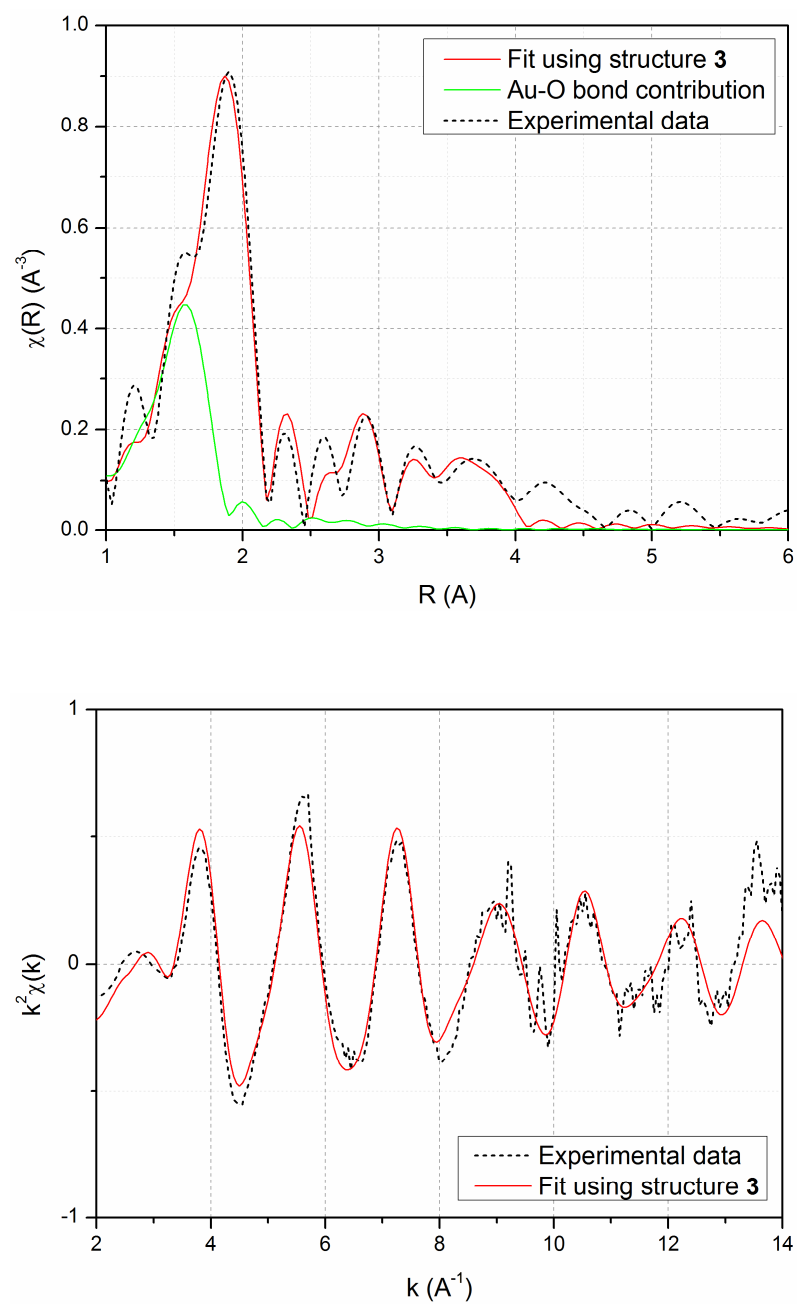

(b)

Fitting to structure 4
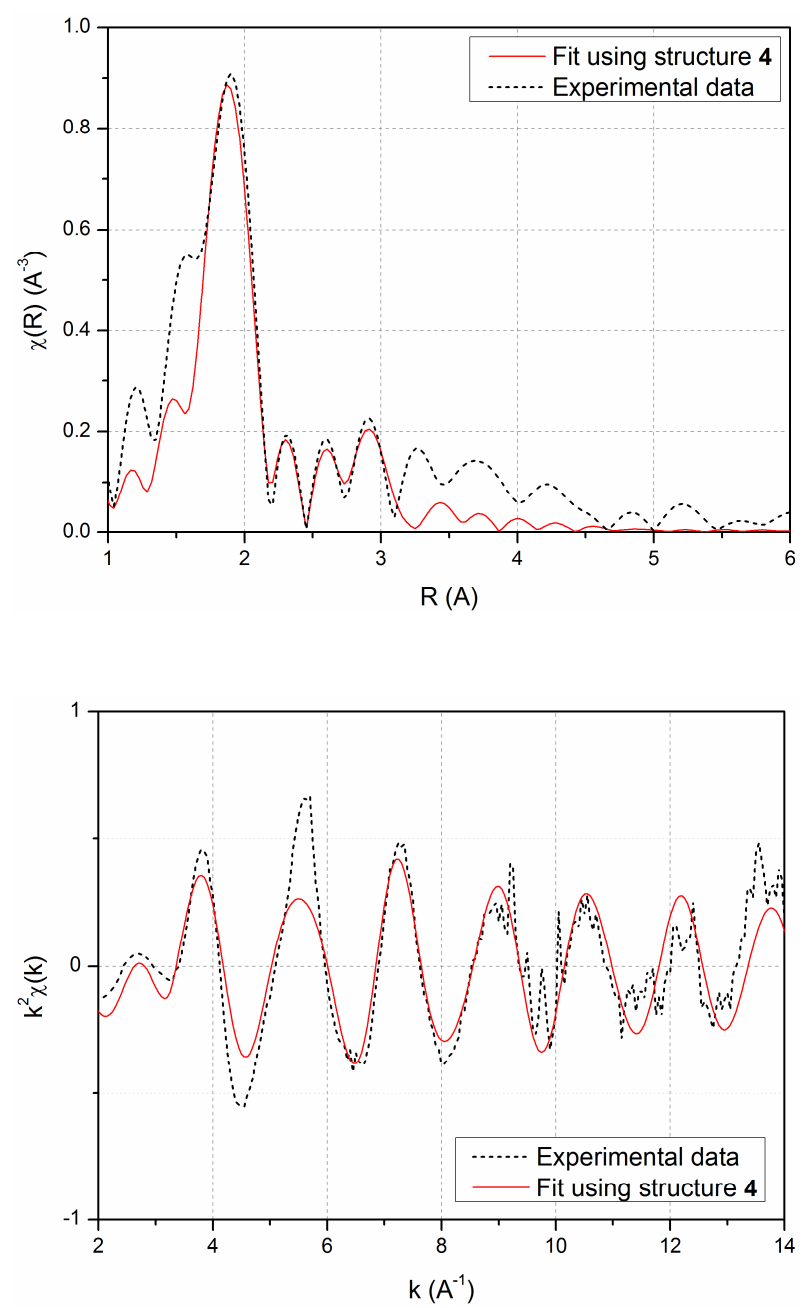

Figure 4. Comparison between EXAFS fits using structure $\mathbf{3}$ and $\mathbf{4}$ using IFEFFIT with FEFF6;

(a) fitting results with structure $\mathbf{3}$ in $R$-space (top) and $k$-space (bottom, $k^{2}$-weighting); (b) fitting results with structure 4 in $R$-space (top) and $k$-space (bottom, $k^{2}$-weighting).

Theoretical calculation of the catalytic pathway of a similar reaction (a 5-endo cyclization over all three carbons of the allene instead of a 5-exo cyclization) by Liu et. al. suggested that the counterion might facilitate the turnover-limiting-step: a 1,3-H-shift of vinyl-gold adduct 5 to 6 (Scheme 2). ${ }^{3 a}$ Consequently, the enantioselectivity could be influenced by the counterion without a direct $\mathrm{Au}-\mathrm{O}$ bond during the catalytic cycle. However, the results of our EXAFS study indicated that in solution there is significant bonding interaction between the gold catalyst and phosphate counterion. ${ }^{31} \mathrm{P}$ NMR spectrum of $\mathrm{Ph}_{3}$ PAuL2 showed no detectable dynamic behavior by line shape analysis. ${ }^{23}$ As the reaction was found to be much faster with $\mathrm{Ph}_{3} \mathrm{PAuL2}$ catalyst (1h at room temperature), albeit 
with lower enantioselectivity, than with $\operatorname{dppm}(\mathrm{AuCl}) 2 / \mathbf{L 1}-\mathrm{Ag}(18 \mathrm{~h}$ at room temperature $),{ }^{12}$ it might be possible to rule out dissociation of the phosphate as the rate determining step although a full kinetic study will be needed to verify this. On the other hand, attempts to observe any intermediates of a catalytic cycloisomerization of $\mathbf{1}\left(25 \mathrm{~mol} \%, \mathrm{R}^{1}, \mathrm{R}^{2}=\left(\mathrm{CH}_{2}\right)_{5}, \mathrm{R}^{3}=\mathrm{Me}, \mathrm{XH}=\mathrm{OH}\right)$ using EXAFS were unsuccessful due to the very fast reaction $(<1$ minute at the concentration required for EXAFS). Nevertheless, the implication of our findings means that direct bonding between the chiral counterion and the metal catalyst should not be ruled out in future mechanistic study of these reactions

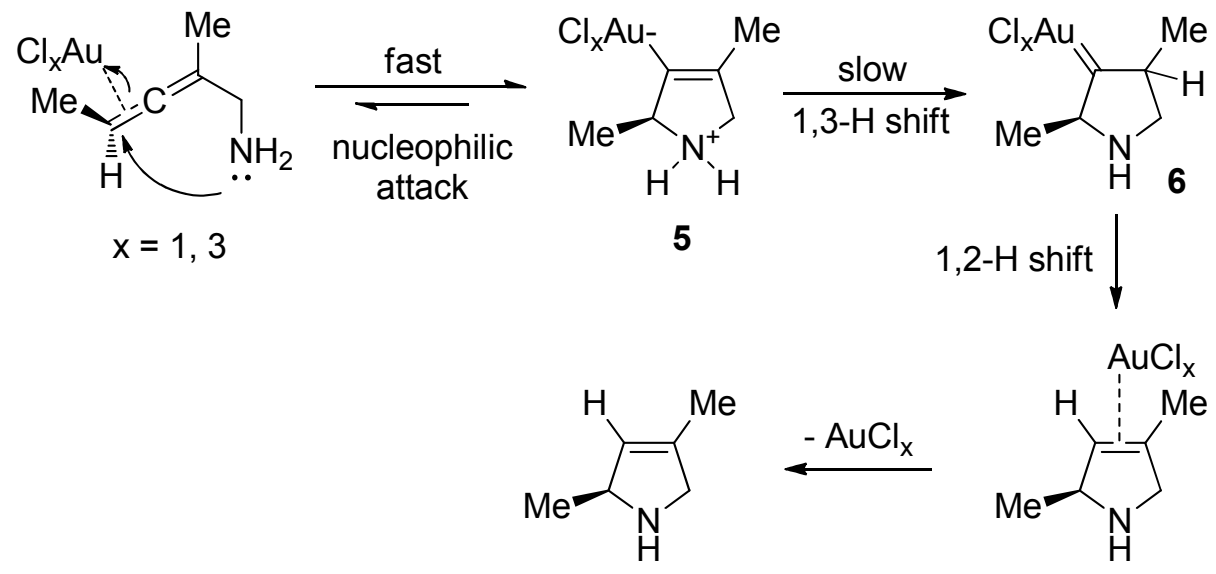

Scheme 2. Calculated mechanism by Liu and co-workers. ${ }^{3 \mathrm{a}}$

Echavarren recently reported the $\mathrm{R}_{3} \mathrm{PAu}$-phosphate catalysts to be unreactive in catalyzing enyne reactions, in contrast to their $\mathrm{R}_{3} \mathrm{PAu}-\mathrm{NTf}_{2}$ analogues. ${ }^{24}$ This implies that the phosphate counterion can remain coordinated to the gold cation under the reaction conditions, in good agreement with our findings.

\section{Gold-catalyzed benzannulation}

The benzannulation reaction reported by Yamamoto poses a different mechanistic question for gold catalysis: the oxidation state of the catalytic species. ${ }^{13}$ Oxidation of $\mathrm{Au}(\mathrm{I})$ species by air or reduction of $\mathrm{Au}(\mathrm{III})$ species by solvent and reactants, such as terminal alkynes, (sometimes to $\mathrm{Au}(0)$ ) are normally facile under reaction conditions and both types of species can exists in solution. Hashmi and Bertagnolli recently reported observation and quantification of $\mathrm{Au}(\mathrm{I})$ and $\mathrm{Au}(\mathrm{III})$ 
complexes in an oxidative esterification reaction. ${ }^{11}$ The Au(III) species dominates during reaction and the $\mathrm{Au}(\mathrm{I})$ species dominates the post reaction mixture, but they are both always present in significant quantities $(>10 \%)$.

A mechanism which involves intramolecular attack of the ketone oxygen atom on the activated triple bond of ketone 7 , followed by a turn-over limiting [4+2] cycloaddition step was proposed by the author (Scheme 3). This general mechanism was later corroborated by theoretical calculation, although the [4+2] cycloaddition was found to be stepwise in nature, first via a Huisgen-type [3+2] cycloaddition (B3LYP/LANL2DZ). ${ }^{3 \mathrm{~b}}$ Importantly, both $\mathrm{Au}(\mathrm{III})$ and $\mathrm{Au}(\mathrm{I})$ catalytic pathways were calculated to have similar activation energy barriers for the turnover limiting step $\left(115 \mathrm{~kJ} \cdot \mathrm{mol}^{-1}\right)$, giving no preference for either oxidation state of the true catalyst.<smiles>CC(=O)c1ccccc1C#Cc1ccccc1</smiles><smiles>CC1([Tl])CCCCC1</smiles>

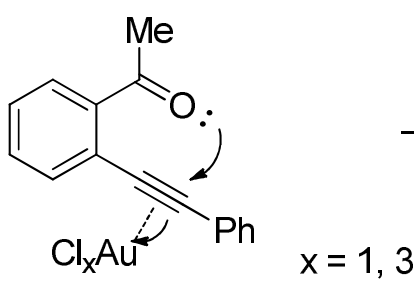
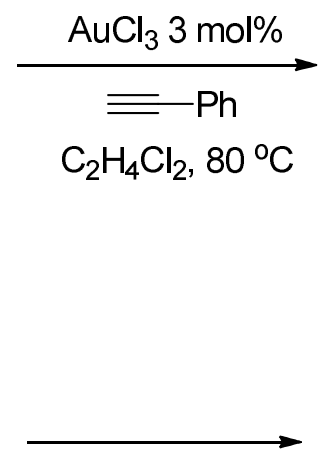<smiles>Cc1cc(-c2ccccc2)c(C(=O)c2ccccc2)c2ccccc12</smiles><smiles></smiles>

$8 \mathbf{a} x=1$

$8 b \quad x=3$

Scheme 3. Proposed mechanism of benzannulation. ${ }^{13}$

We reasoned that since the cycloaddition step is the turnover limiting step, the benzopyriliumaurate intermediate 8 (Scheme 3) should be observable to EXAFS at room temperature, ${ }^{25}$ given that EXAFS is sensitive to the oxidation state and coordination number of the observed atom. Furthermore, in the absence of phenylacetylene and heating, the major species $\mathbf{8 a}$ or $\mathbf{8 b}$ should be identifiable. Addition of ketone 7 (1.0 equivalent) into a solution of $\mathrm{AuCl}_{3}$ in acetonitrile resulted in 
immediate color change from light yellow to deep brown." Due to the high absorbance of 1,2dichlorethane at $9 \mathrm{keV}$, acetonitrile was used for our study. This has been reported to be a suitable alternative solvent for the reaction. ${ }^{13}$ The normalized EXAFS spectra of the reaction mixture was compared to a solution of $\mathrm{AuCl}_{3}$ and a solution of vinyl-gold(I) complex $\mathbf{9}^{26}$ in acetonitrile (Figure 5a). The XANES region of these spectra, particularly the white-line intensity, clearly indicated that the solution formed by reacting $\mathrm{AuCl}_{3}$ with 7 resembles $\mathrm{AuCl}_{3}$ far more than it does 9 . A small peak at about $1.5 \AA$ in $R$-space (Figure $5 \mathrm{~b}$ ) was observed for the reaction mixture, which suggests the formation of an $\mathrm{Au}-\mathrm{C}$ bond in $\mathbf{8}$. In addition, little loss in signal magnitude in both $R$-space and $k$ space indicates that most of the chloride anion is still coordinated to gold which means that the majority of gold species in solution are still $\mathrm{Au}(\mathrm{III})$ complexes. Importantly, no evidence for $\mathrm{Au}-\mathrm{Au}$ interaction in a gem-digold intermediate, as proposed by Gagné and Fürstner, ${ }^{27}$ was detected when these were compared to the spectrum of gold foil. Addition of an excess of phenylacetylene to the reaction mixture at room temperature resulted in a very similar EXAFS spectra, with possible increase in coordination number of gold and white line intensity consistent with a dominant $\mathrm{Au}(\mathrm{III})$ species (see Table S1, supporting information).
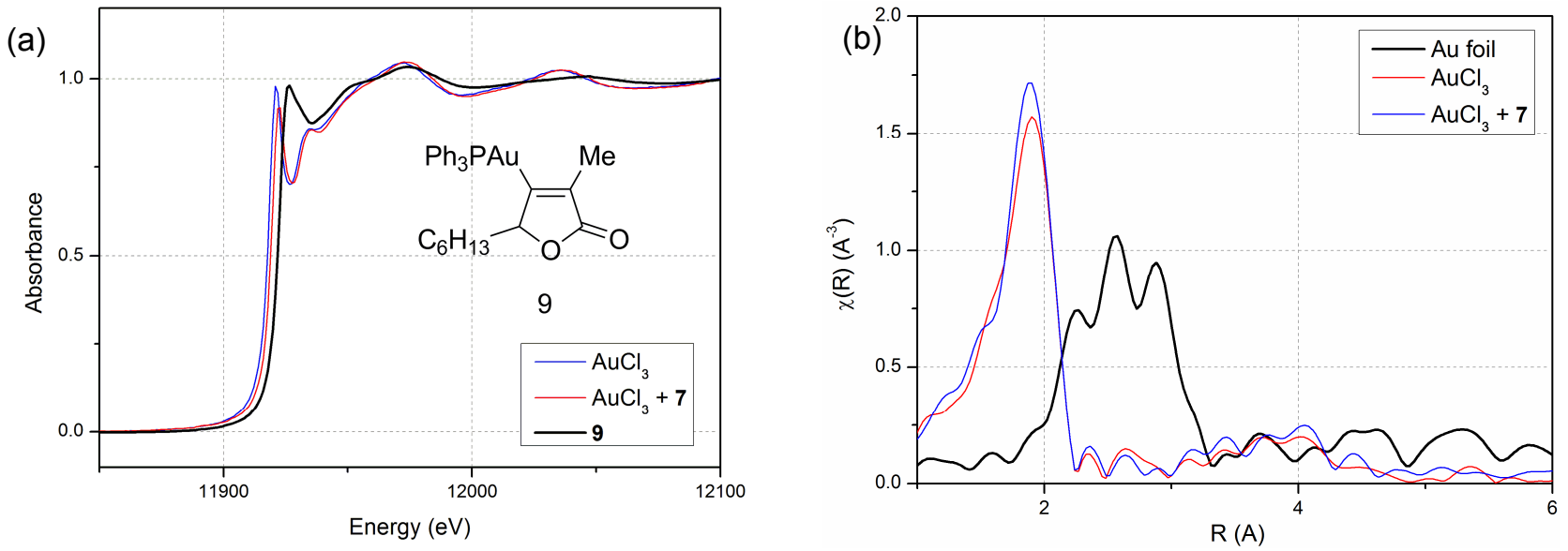

Figure 5. Comparison between spectra of $\mathrm{AuCl}_{3}, \mathrm{Au}$ foil, $7+\mathrm{AuCl}_{3}(50 \mathrm{mM}$ in acetonitrile) and 9 (50 $\mathrm{mM}$ in acetonitrile) (a) XANES spectra of 9, $\mathrm{AuCl}_{3}, \mathrm{AuCl}_{3}+7$, (b) EXAFS spectra of Au foil, $\mathrm{AuCl}_{3}$ and $\mathrm{AuCl}_{3}+7$ in $R$-space ( $k^{2}$-weighting).

The catalytic reaction was performed at $80{ }^{\circ} \mathrm{C}$ while our experiments were carried out at room temperature to ensure the observation of the resting-state species of the catalytic cycle. 
The similarity between the EXAFS spectra of $\mathrm{AuCl}_{3}$ and $7+\mathrm{AuCl}_{3}$ raised questions about the homogeneity of the reaction mixture and if significant amount of $\mathrm{AuCl}_{3}$ were left unreacted. This was addressed by performing a titration of a solution of 7 with $\mathrm{AuCl}_{3}$ and examining the contents of the solutions using ${ }^{1} \mathrm{H}$ and ${ }^{13} \mathrm{C}$ NMR. Upon addition of 0.5 equivalent of $\mathrm{AuCl}_{3}$, several new products were clearly observed. Addition of another 0.5 equivalent of $\mathrm{AuCl}_{3}$ led to complete consumption of 7 and the emergence of three different acetyl signals (Figure 6). The general downfield shift of all signals is consistent with the formation of a benzopyrilium cation. ${ }^{28}$ In addition, the carbonyl signal of ${ }^{13} \mathrm{C}$ NMR moved from $201.3 \mathrm{ppm}$ for 7 to $188.6 \mathrm{ppm}$ upon addition of $\mathrm{AuCl}_{3}$. The assignment of this signal was confirmed by $\mathrm{HMBC}$ correlation (see supporting information) to the acetyl signal at $3.4 \mathrm{ppm}$. This change was accompanied by the disappearance of alkyne carbon signals in 7 (95.4 ppm and $89.8 \mathrm{ppm})$, indicating transformation of 7 to a vinyl-gold complex. This structural information agrees with a general structure similar to 8 (Scheme 3). However, integration of the acetyl and aromatic region in ${ }^{1} \mathrm{H}$ NMR after addition of 0.5 equivalent of $\mathrm{AuCl}_{3}$ suggests that the major species is generated from a $>1: 1$ stoichiometry of 7 to $\mathrm{AuCl}_{3}$. $\mathrm{A}$ more quantitative assessment was not possible due to the quadrupolar effect of gold. Nevertheless, our XAFS and NMR evidence is indicative of a gold species with more than one benzopyrilium cation attached. A similar divinyl-gold(III) species was proposed to explain dimerized products observed in a similar intramolecular 5-endo hydroalkoxylation of allenes. ${ }^{29}$ 

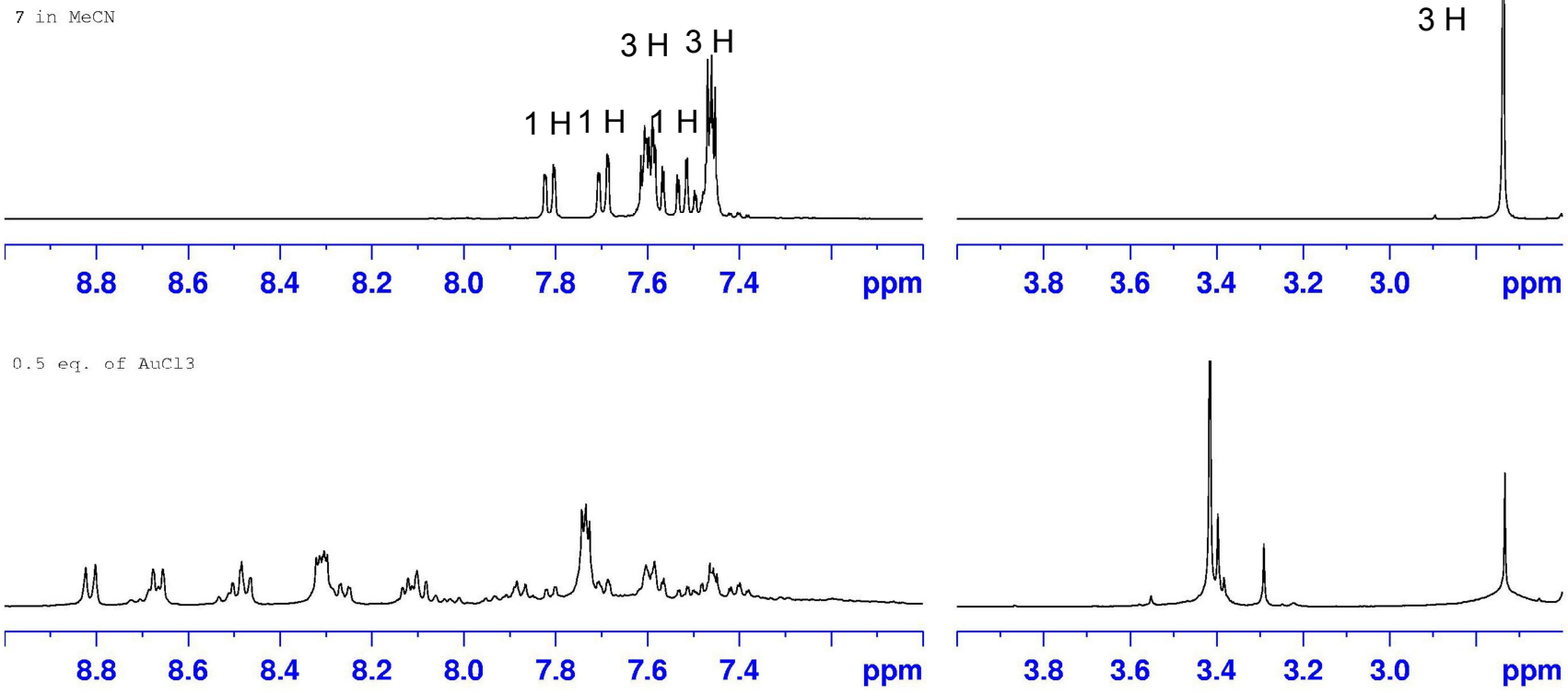

1.0 eq. of $\mathrm{AuCl} 3$
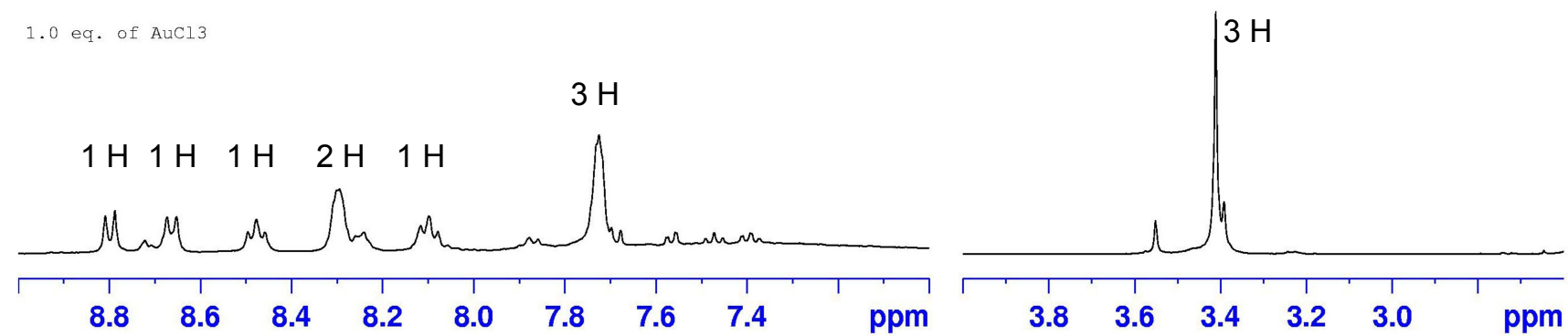

Figure 6. ${ }^{1} \mathrm{H}$ NMR spectra of titration experiment of compound $7(120 \mathrm{mM})$ with $\mathrm{AuCl}_{3}(300$ $\mathrm{mM})$ in acetonitrile- $d_{3}$.

ESI mass spectrometry provided further support of this hypothesis. The major species generated from a 1:1 mixture of $\mathrm{AuCl}_{3}$ and 7 was found to be a previously unknown complex 10 (Figure 7), with two cyclized molecules coordinated to one gold atom, probably in trans geometry. Complexes with monobenzopyrilium-gold complexes were also observed with both oxidation states +1 and +3 (11 and 12), but with much lower signal intensity. The combined results of EXAFS, NMR and ESIMS suggest complex $\mathbf{1 0}$ is the major gold species in the $1: 1$ solution of $\mathbf{7}: \mathrm{AuCl}_{3}$, making up to about $43 \%$ of all gold complexes (unreacted $\mathrm{AuCl}_{3}$ makes up another $43 \%$ ), based on ${ }^{1} \mathrm{H} \mathrm{NMR}$ integration of the acetyl signals. Under realistic catalytic conditions, i.e. a large excess of 7, the equilibrium will favor the formation of complex 10. Two diastereoisomers (10a and 10b), which may exist in equilibrium, are possible. However, it is impossible to differentiate them in ${ }^{1} \mathrm{H}$ NMR even at low temperature due to significant broadening of the signals by the quadrupolar effect of 
gold. Heating this mixture with 1 equivalent of phenylacetylene leads to formation of the product $\left(\left[\mathrm{M}+\mathrm{H}^{+}\right] m / z=323\right.$, supporting information).

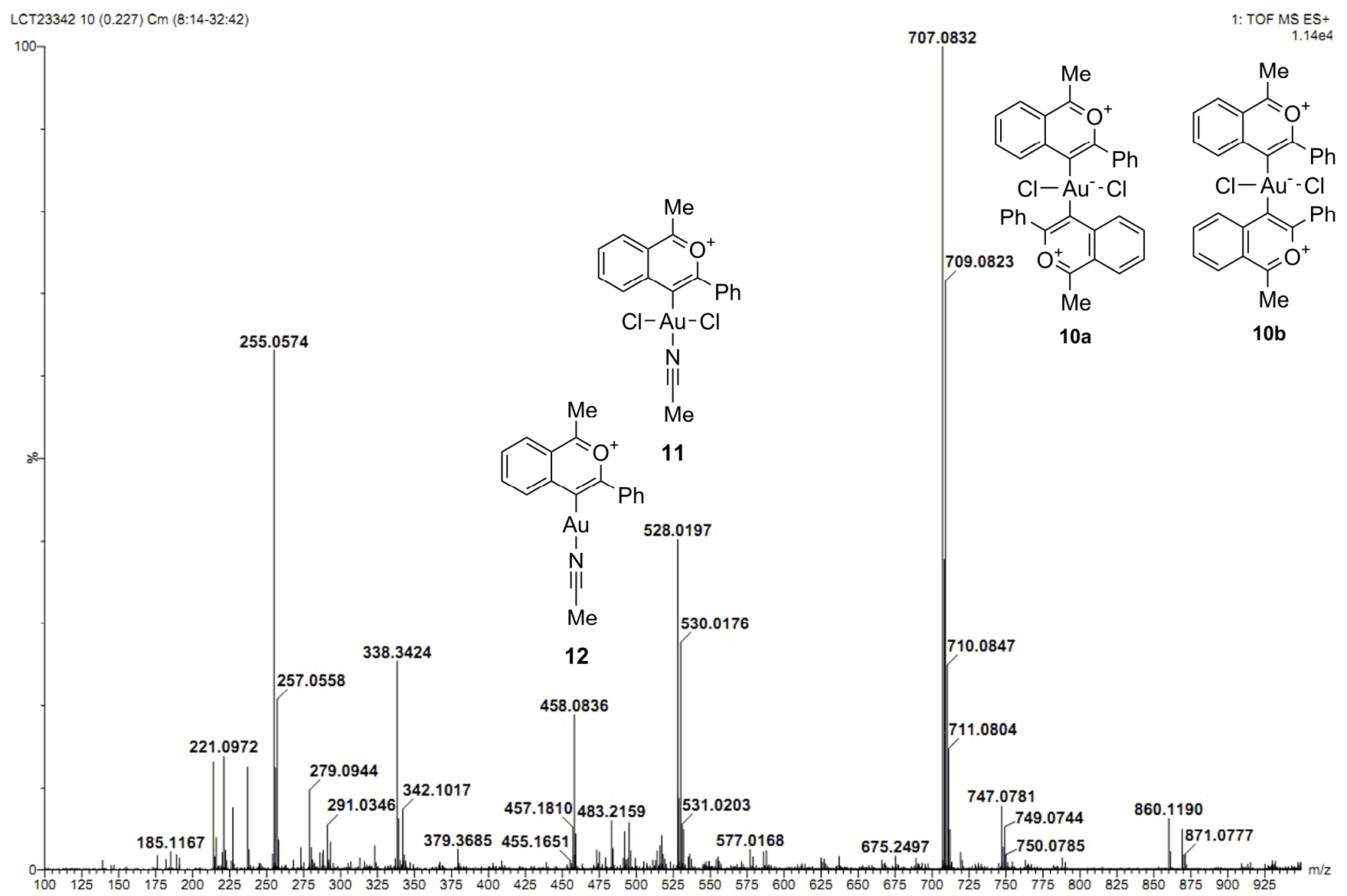

Figure 7. ESI-MS spectrum of 1:1 mixture of 7 and $\mathrm{AuCl}_{3}$.

Our spectroscopic evidence supports novel Au(III) complex $\mathbf{1 0}$ being the major species in goldcatalyzed benzannulation of 2-carbonylphenylalkynes. While previous theoretical calculation proposed a $\mathrm{Au}(\mathrm{I})$ catalytic cycle to be equally possible, ${ }^{3 \mathrm{~b}}$ little evidence of these intermediates were observed in our present study.

\section{Conclusions}

Our study utilized solution-based EXAFS as a powerful analytical tool to complement NMR spectroscopy and mass spectrometry, in this case, to deconvolute the role of chiral phosphate anion and the oxidation state of gold in gold catalyzed reactions. Fitting results of the EXAFS spectrum of the $\mathrm{Ph}_{3} \mathrm{PAuL} 2$ complex in solution indicated the existence of a strong bond between the phosphate oxygen and gold cation. This bond was found to be non-dynamic by ${ }^{31} \mathrm{P}$ NMR, implying that the 
phosphate may stay coordinated to gold cation during the catalytic cycle, essentially acting as a ligand. While it is not possible to rule out a phosphate-assisted proton-transfer stereochemical determining step, direct bonding between the chiral phosphate counterion and the metal catalyst should be given due consideration in this type of reactions.

In the second study on gold-catalyzed benzannulation of 2-carbonylphenylalkyne, spectroscopic data (EXAFS, NMR, MS) indicated Au(III) complex 10 to be the major species in solution. Little evidence was found to support the presence of $\mathrm{Au}(\mathrm{I})$ gem-diaurate intermediates, which have been proposed for similar reactions.

ACKNOWLEDGMENT Work conducted at the Swiss Light Source was supported by the European Commission under the 6th Framework Programme (Strengthening the European Research Area, Research Infrastructures. Contract no: RII3-CT-2004-506008). We thank Dr Szlachetko for his assistance at the SuperXAS beamline. BNN thanks the Ramsay Memorial Trust for his fellowship. LA thanks Xunta de Galicia (Angeles Alvariño program) and EB thanks the Fundación Pedro Barrié de la Maza for postdoctoral support.

SUPPORTING INFORMATION PARAGRAPH Details on the preparation of compounds, NMR and MS experiment, experimental setup and EXAFS spectra fitting are included in Supporting Information. Molecular modeling was performed using Gaussian 09 package and the results can be found at http://hdl.handle.net/10042/to-11619.

\section{References}

1. (a) Huang, H.; Zhou, Y.; Liu, H. Beilstein J. Org. Chem. 2011, 7, 897; (b) Arcadi, A. Chem. Rev. 2008, 108, 3266; (c) Hashmi, A. S. K. Chem. Rev. 2007, 107, 3180; (d) Hashmi, A. S. K.; Hutchings, G. J. Angew. Chem. Int. Ed. 2006, 45, 7896; (e) Hoffmann-Röder, A.; Krause, N. Org. Biomol. Chem. 2005, 3, 387.

2. Hashmi, A. S. K. Angew. Chem. Int. Ed. 2010, 49, 5232. 
3. (a) Zhu, R.-X.; Zhang, D.-J.; Guo, J.-X.; Mu, J.-L.; Duan, C.-G.; Liu, C.-B. J. Phys. Chem. A 2010, 114, 4689; (b) Straub, B. F. Chem. Commun. 2004, 1726.

4. Koningsberger, D. C.; B.L.Mojet; a, G. E. v.; Ramaker, D. E.; Babiak, S. Topics in Catalysis 2000, 10, 143.

5. Abdul Rahman, M. B. B.; Bolton, P. R.; Evans, J.; Dent, A. J.; Harvey, I.; Diaz-Moreno, S. Faraday Discuss. 2002, 122, 211; Evans, J. Chem. Soc. Rev. 1997, 26, 11.

6. Bauer, M.; Heusel, G.; Mangold, S.; Bertagnolli, H. J. Synchrotron Rad. 2010, 17, 273.

7. Bartlett, S. A.; Wells, P. P.; Nachtegaal, M.; Dent A. J.; Cibin, G.; Reid, G.; Evans, J.; Tromp, M. J. Cat. 2011, 284, 247; Tromp, M; van Strijdonck, G. P. F.; van Berkel, S. S.; van den Hoogenband, A.; Feiters, M. C.; de Bruin, B.; Fiddy, S. G.; van der Eerden, A. M. J.; van Bokhoven, J. A.; van Leeuwen, P. W. N. M., Koningsberger, D. C. Organometallics, 2010, 29, 3085.

8. Jutz, F.; Grunwaldt, J.-D.; Baiker, A. J. Mol. Cat. A: Chemical 2009, 297, 63.

9. Tromp, M.; van Bokhoven, J. A.; van Haaren, R. J.; van Strijdonck, G. P. F.; van der Eerden, A. M. J.; van Leeuwen, P. W. N. M.; Koningsberger, D. C. J. Am. Chem. Soc. 2002, 124, 14814.

10. Guilera, G.; Newton, M. A.; Polli, C.; Pascarelli, S.; Guin, M.; Hii, K. K. Chem. Commun. 2006, 4306.

11. Hashmi, A. S. K.; Lothschütz, C.; Ackermann, M.; Doepp, R.; Anantharaman, S.; Marchetti, B.; Bertagnolli, H.; Rominger, F. Chem. Eur. J. 2010, 16, 8012.

12. Hamilton, G. L.; Kang, E. J.; Mba, M.; Toste, F. D. Science 2007, 317, 496.

13. Asao, N.; Takahashi, K.; Lee, S.; Kasahara, T.; Yamamoto, Y. J. Am. Chem. Soc. 2002, 124, 12650.

14. for other examples using chiral phosphate counterions, see Patil, N. T.; Mutyala, A. K.; Konala, A.; Tella, R. B. Chem. Commun. 2012, 48, DOI: 10.1039/C2CC17450B; Rauniyar, V.; Wang, Z. J.; Burks, H. E.; Toste, F. D. J. Am. Chem. Soc. 2011, 133, 8486; LaLonde, R. L.; Wang, Z. J.; Barbazanges, M.; Augé, M.; Moussa, J.; Amouri, H.; Aubert, C.; Desmarets, C.; Fensterbank, L.; Gandon, V.; Malacria, M.; Ollivier, C. Chem. Eur. J. 2011, 17, 13789; Mba, M.; Lackner, A. D.; 
Toste, F. D. Angew. Chem. Int. Ed. 2010, 49, 598; Komanduri, V.; Krische, M. J. J. Am. Chem. Soc. 2006, 128, 16448.

15. (a) Llewellyn, D. B.; Adamson, D.; Arndtsen, B. A. Org. Lett. 2000, 2, 4165; (b) Dorta, R.; Shimon, L.; Milstein, D. J. Organomet. Chem. 2004, 689, 751; (c) Chen, D.; Sundararaju, B.; Krause, R.; Klankermayer, J.; Dixneuf, P. H.; Leitner, W ChemCatChem 2010, 2, 55.

16. Gimeno, M. C.; Laguna, A. Chem. Rev. 1997, 97, 511, and references therein.

17. Aikawa, K.; Kojima, M.; Mikami, K. Adv. Syn. Cat. 2010, 352, 3131.

18. Reaction was performed at room temperature in toluene as described by Toste and coworker. The enantioselectivity was determined by optical rotation measurement.

19. In a separated experiment, catalysts prepared with and without filtration were shown to give similar yield with substrate $\mathbf{1}\left(\mathrm{R}^{1}, \mathrm{R}^{2}=\left(\mathrm{CH}_{2}\right)_{5}, \mathrm{R}^{3}=\mathrm{Me}, \mathrm{XH}=\mathrm{OH}\right)$ after 30 minutes.

20. Newville, M. J. Synchrotron Radiat. 2001, 8, 322.

21. For comparison, a statistical analysis of 96 crystal structures in the Cambridge Structural Database with $\mathrm{P}-\mathrm{Au}-\mathrm{O}$ motif gave the average bond lengths for $\mathrm{Au}-\mathrm{O}$ and $\mathrm{Au}-\mathrm{P}$ as $2.06 \AA$ and $2.22 \AA$, respectively.

22. Sokolov, A.; Sizova, O. Russ. J. Gen. Chem. 2010, 80, 1223.

23. see Figure S1, Supporting information.

24. Raducan, M.; Moreno, M.; Bour, C.; Echavarren, A. M. Chem. Commun. 2012, 48, 52.

25. A similar species has recently been characterized by IR and ${ }^{1} \mathrm{H}$ NMR: Döpp, R.; Lothschütz, C.; Wurm, T.; Pernpointner, M.; Keller, S.; Rominger, F.; Hashmi, A. S. K. Organometallics, 2011, 30,5894

26. Liu, L.-P.; Xu, B.; Mashuta, M. S.; Hammond, G. B. J. Am. Chem. Soc. 2008, 130, 17642.

27. (a) Weber, D.; Tarselli, M. A.; Gagné, M. R. Angew. Chem. Int. Ed. 2009, 48, 5733; (b) Seidel, G.; Lehmann, C. W.; Fürstner, A. Angew. Chem. Int. Ed. 2010, 49, 8466.

28. Gong, W.-T.; Ning, G.-L.; Li, X.-C.; Wang, L.; Lin, Y. J. Org. Chem. 2005, 70, 5768.

29. Hashmi, A. S. K.; Blanco, M. C.; Fischer, D.; Bats, J. W. Eur. J. Org. Chem. 2006, 71, 1387. 
FOR TABLE OF CONTENTS USE ONLY

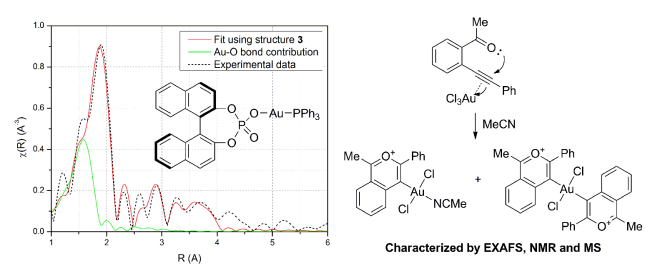

